\title{
Factors determining self-harm
}

\author{
YLShakya, RAcharya, MPGupta, Banjara MR, PN Prasad \\ Department of General Practice \& Emergency, Tribhuvan University Teaching Hospital, Kathmandu
}

Correspondence to: Dr. Yagya Laxmi Shakya, Lecturer, Tribhuvan University Teaching Hospital.

E-mail: yagya70@yahoo.com

Introduction: Self-harm forms a significant proportion of patient attending in emergency departments, typically 10-30 per 100000 people commit suicide annually. The objective of this study was to find out the factors responsible for self harm.

Methods: This is a cross sectional study of 100 patients of self harm coming to Emergency Department of Tribhuvan University Teaching Hospital from $1^{\text {st } O c t o b e r ~} 2007$ to $31^{\text {st }}$ March, 2008. Questionnaire about demographic information of patient along with details about cause of self harm, and any other illnesses associated was filled. Information about duration of arrival in emergency department, place of self harm was gathered. Patients were clinically examined and hematological and biochemical tests including liver function test and the type of poison used and its level in blood were examined.

Results: Total number of patients with self harm was 100 (female - 71\%; male- 29\%).Among female, 16-30 years age group to be the largest $(76 \%)$. Mean duration of arrival in emergency department was 3.08 hour. Metacid ingestion (29\%) was found to be the most common cause for self harm. There is no difference of self harm for suicide and threat cause. Only $5 \%$ of patient with self harm has psychiatry illness in the past.

Conclusions: Self harm forms a significant proportion of patient attending the Emergency department and the most common form of self harm used was metacid ingestion. There is compelling evidence for the need to improve delivery of care for patients who inflict self harm.

Key words: Cause, emergency department, self harm.

\section{Introduction}

People who engage in self-harm form a significant proportion of patient attending in emergency departments. ${ }^{2}$ Typically 10-30 per 100000 people commit suicide annually. Both fatal and non fatal deliberate self harm constitute considerable public health problems .There is compelling evidence for the need to improve the delivery of care for patients who self harm and to improve the training supervision, support and co-ordination of staff group's delivery that care. ${ }^{3}$ Patients presenting with self harm usually have current psychosocial difficulties and are likely to be suffering from mental health problems and are at significant risk of further self harm and suicide. ${ }^{5}$

Prevention of suicide is now included in health policy initiatives in several countries.

Action to reduce suicide needs to be taken at all levels of the organization and role of the suicide prevention needs to include support, training and development as well as specific time limited therapy with a highly targeted group of patients at specific risk. ${ }^{15}$

This research study was conducted from $1^{\text {st }}$ October to March 2008 at Tribhuvan University Teaching Hospital in Emergency Department to find out the factors responsible for self harm in patients.

\section{Methods}

This was a cross sectional study of 100 patients of self harm coming to Emergency Department of Tribhuvan 
University Teaching Hospital. It is one of the largest hospitals in Nepal and its Emergency is one of the busiest departments in the country. The total numbers of patients attending in out patient department is on an average 1000 per day and on average 200 patients per day attend the emergency department. Among them, monthly average 100 patients come with history of self harm.

All the patients coming to emergency department with history of self harm during 1st October 2007 to 31st March 2008 were included in the study. Hundred patients of self harm attended during that period. Both male and female above 15 years were included in this study. Adult patients (above 15 years) who were conscious and required health care treatment following self reported act of self harm, intentionally self harm patients were included in this study. Patients aged less than 14 years and where self poisoning was accidental, accidentally burn cases, vehicle accidents, accidental ingestion of drugs were excluded.

Background information collected included details of age, sex, marital status, ethnicity, employment, location, education level. Any treatment or history of mental health problems, previous history of self harm was recorded. They were asked for the cause of self harm, and whether it is first attempt or repetition. Data was entered and analyzed using SPSS version 11.5. Descriptive analysis was done using percentages, means, standard deviations and ranges.

\section{Results}

Most of the patients of self harm were of the teenage age group. Forty five percent patients were of age group 21-30 years followed by 31 percent of 16-20 years age group. Studies showed that self harm was more common in female. Out of 100 patients, self harm was found to be more common in female $71 \%$ and $29 \%$ in male. Self harm was equally common among married and unmarried. People with secondary level of education were more involved in self harm (26\%) followed by bachelor level and above (21\%).

Out of 100 patients, self harm was more common in students (32\%). Among them, 21 were females and 11 were males.

Among 100 patient, suicidal and threat causes were found to be not much different $49 \%$ and $51 \%$.

Table 1: Cause of self harm and gender of the patient

$\begin{array}{llll}\text { Causes } & \text { Female }(\%) & \text { Male }(\%) & \text { Total }(\%) \\ \text { Suicidal } & 32(45.1) & 17(58.6) & 49(49.0) \\ \text { Threat } & 39(54.9) & 12(41.4) & 51(51.0) \\ \text { Total } & \mathbf{7 1 ( 1 0 0 )} & \mathbf{2 9}(\mathbf{1 0 0}) & \mathbf{1 0 0}(\mathbf{1 0 0 . 0})\end{array}$

Among 5 self harm patient of less than 15 years, $4(80 \%)$ committed self harm for suicidal attempt whereas $1(20 \%)$ was for threat. However, in age group 16-20, suicidal cause was $13(41.9 \%)$ and for threat $18(58.0 \%)$. In age group 2130 , among 45 suicidal causes, $21(41.7 \%)$ was for suicidal and $24(53.3 \%)$ was for threat. Similarly, in age group 31-50, among 17 cases, $10(58.8 \%)$ was for suicidal and 7 (41.2\%) was for threat. For more than 50 years age group, 1 (50.0\%) was suicidal while the other $1(50.0 \%)$ was for threat.

Table2: Age and cause of self harm

\begin{tabular}{llll} 
Category of age & \multicolumn{2}{c}{ Cause of self harm } & Total $(\%)$ \\
& Suicidal $(\%)$ & Threat $(\%)$ \\
\hline 15 years & $4(80.0)$ & $1(20.0)$ & $5(100.0)$ \\
16-20 years & $13(41.9)$ & $18(58.0)$ & $31(100.0)$ \\
21-30 years & $21(46.7)$ & $24(53.3)$ & $45(100.0)$ \\
31-50 years & $10(58.8)$ & $7(41.2)$ & $17(100.0)$ \\
$>50$ years & $1(50.0)$ & $1(50.0)$ & $2(100.0)$
\end{tabular}

Among 11 illiterate patients, $8(72.73 \%)$ were of suicidal case and 3 (27.27) were threat. Majority, $26 \%$ cases attended with the qualification of secondary level, among which 13 $(50 \%)$ were suicidal and $13(50 \%)$ were threat. However, among the higher secondary group, cause of self harm was $13(72.72 \%)$ due to threat and only $5(27.78 \%)$ was due to suicide.

Among total 71self harm patient for suicidal attempt, 38 (53.5\%) used poison and among 29 self harm patient for threat (62.1\%) used poison. Similarly, 27 (38.0\%) took drugs and among 29 patients for threat, $10(34.5 \%)$ patients used drugs. Metacid ingestion (29\%) was found to be most common cause for the self harm. Next common poison for self harm was Zinc Phosphate (18\%), followed by Paracetamol poisoning (16\%). Four percent came with history of self inflicted injuries and 3\% came with the history of strangulation. Multiple Drug ingestion was $6 \%$ and others (Benzodiazepam 4\%, other insecticide 6\%).

Table 3: Poison / Drugs and cause for self harm

\begin{tabular}{llll} 
Substance & \multicolumn{2}{c}{$\begin{array}{c}\text { Cause of self harm } \\
\text { Suicidal }(\%)\end{array}$} & Threat $(\%)$ \\
Poison & $38(53.5)$ & $18(62.1)$ & $56(56.0)$ \\
Drugs & $27(38.1)$ & $10(34.5)$ & $37(37.0)$ \\
Hanging & $1(1.4)$ & $0(0.0)$ & $1(1.0)$ \\
Mercury \& spirit & $0(0)$ & $1(3.4)$ & $1(1.0)$ \\
Self inflicted & & & \\
incised injury & $3(4.2)$ & $0(0.0)$ & $3(3.0)$ \\
Strangulation & $2(2.8)$ & $0(0.0)$ & $2(2.0)$ \\
Total & $71(100.0)$ & $29(100.0)$ & $100(100.0)$
\end{tabular}

Out of 100 patients, 7 (7\%) used other substances and 
methods for self harm. Among them, $6(8.5 \%)$ were female and $1(3.4 \%)$ male. Among other causes of self harm, self inflicted injuries were 3 (3\%), all were female followed by strangulation 1 male and 1 female each; hanging- 1 female, mercury and spirit-1.

Five percent of the patients had history of psychiatry illness and $4 \%$ had other illness. This indicates that the problem of self harm is the independent factor.

Mean duration of arrival in emergency department was 3.08 hours (Min 0.25, Max 22). Majority of patients 51\% arrived in Emergency department within half an hour. Most of the patient arrived in time in emergency which made patient treatment and management easier.

Table 4: Duration of seeking treatment after self harm

$\begin{array}{lll}\text { Duration } & \text { Frequency } & \text { Percent } \\ \text { Less than one hour } & 51 & 51.0 \\ 1-2 \text { hours } & 28 & 28.0 \\ \text { 2-4 hours } & 9 & 9.0 \\ 4-8 \text { hours } & 12 & 12.0\end{array}$

Ninety-nine percent of patients had committed self harm within their homes.

\section{Discussion}

This study showed that self harm has a varied etiology. In our study, majority of patients came with self poisoning. However, other study reported higher proportion of self injury compared with self poisoning. Metacid ingestion was most common poison used for self harm. Metacid is easily available in Nepal without prescription. So it may be one of the factor people are commonly using. Next common poison for self harm was Zinc Phosphate (18\%), followed by Paracetamol poisoning. Self harm was found to be more common in female than in male similar to the other studies. ${ }^{16}$ This can be due to illiteracy and more dependent. The most common age group (16-30 years) was found to be involved in self harm was $76 \%$ and mostly they had secondary level education. There is compelling evidence for need to improve the delivery of care for patients who self harm. Self harm was equally common among married and unmarried. Suicidal and threat causes were found to be not much different $49 \%$ and $51 \%$. Mean duration of arrival in emergency department was 3.08 hours (Min 0.25, Max 22). Majority of patients $51 \%$ arrived in Emergency department within half an hour. $99 \%$ of patients had committed self harm within their homes. Many studies reported that self harm is more common in urban areas. Our study also suggests that $96 \%$ people belonged to urban areas. $5 \%$ of the patients had history of psychiatry illness. This indicates that the problem of self harm is the independent factor. However, one study reported that half of the patients had a history of psychiatric illness. ${ }^{14}$

Many studies reported that self harm is more common in urban areas. Our study also suggests that $96 \%$ people belonged to urban areas.

\section{Conclusions}

Organophosphorus ingestion was most common poison used for self harm followed by Zinc Phosphate and Paracetamol. Action to reduce suicide needs to be taken at all levels of the organization and role of the suicide prevention needs to include support, and trainings.

\section{Acknowledgements}

We would like to acknowledge Dr Anand Ballabh Joshi, Associate Professor, Professor CK Gurung, Mr Shiva Raj Adhikari, Associate Professor Mandira Shahi and house officers of Emergency Department of the Tribhuvan University Teaching Hospital. This study was funded by DelPHE project of the Institute of Medicine.

\section{References}

1. Bille-Brahe U, Anderson K, Wassserman D et al. The WHO-EURO Multi-centre study: risk of parasuicide and the comparability of the areas under study Crisis Medline 1996; 17: 32-42.

2. Jacob R., Clare C.H., Holland A., Watson P.C., Maimaris C. \& Gunn M. Self harm, capacity and refusal of treatment: implications for emergency medical practice. A prospective observational study. Emergency Medicine Journal 2005; 22: 799-802.

3. Broadhurst M, Gill P. Repeated self-injury from a liaison psychiatry perspective. Advances in Psychiatric Treatment 2007; 13: 228-335.

4. Isacsson G, Charles LR. Management of patients who deliberately harm themselves. BMJ 2001; 322: 213-215.

5. Mitchell AJ, Dennis M. Self harm and attempted suicide in adults: 10 practical questions and answers for emergency department staff. Emergency Medicine Journal 2006; 23: 251-255.

6. Rodham K, Hawton K, Evans E. Reasons for deliberate self harm: Comparison of self poisoner and self cutters in a community sample of adolescent. J Am Acad Child Adolesc Psychiatry 2004; 43: 80-7.

7. Hjelmeland H., Hawton K., Nordvik H, et al. Why people engage in parasuicide: a cross-cultural study of 
intentions. Suicide life Threat Behav 2002; 32: 381-393.

8. Suokas J., Suominen K, Isometsa E, et al. Long term risk factors for suicide mortality after attempted suicide - findings of a 14 year follow study. Acta Psychiatric Scand 2001; 104: 117-121.

9. Owens D, Darren C, Greenwood TH, Dennis M. Mortality and suicide after non-fatal self-poisoning: 16-year outcome study. The British Journal of Psychiatry 2005; 187: 470-475.

10. Schneider B, Maurer K, Frolich L. Dementia and suicide. Fortschr No 2005; 4: 164-169.

11. Healy D. Lines of evidence on the risks of suicide with selective serotonin reuptake inhibitors. Psychother Psychosomat 2003; 72: 71-79.

12. Medawar C, herxheimer A, Bell A., Jofre S. Paroxetine, Panorama and user reporting of ADRs: Consumer intelligence matters in clinical practice and post marketing drug surveillance. Int J Saf Med 2002; 15: 161-169.

13. Whittington C. J., Kendell T, Fonagy P, Cottrell D, Cotgrove A, Boddington E. Selective serotonin reuptake inhibitors in childhood depression: systematic review of published versus unpublished data. Lancet 2004; 363: 1341-1345.

14. Jick S.S., Dean A.D., Jick H. Antidepressants and the risk of suicidal behaviors. JAMA 2004; 292: 338-343.

15. Repper J. A review of the literature on the prevention of suicide through interventions in accident and emergency departments. J Clin Nurs 1999; 8(1): 3-12.

16. Hawton K, Fagg J., Simkin S., Bale E., Bond A. Trends in deliberate self-harm in Oxford, 1985 - 1995: Implications for clinical services and the prevention of suicide. Br J psychiatry 1997; 171: 556- 560.

17. Department of Health. National suicide prevention strategy for England. London DoH, 2002.

18. Hawton K, Karen R, Emma E, Rosamund W. Deliberate Self-harm in adolescents: Self report survey in schools in England. BMJ 2002; 325: 1207-1211. 